\title{
Taking AIM: Integrating Organization Development into the Creation of a Diversity, Equity, and Inclusion Audit
}

\author{
Kawanna Bright \\ University of Denver, USA \\ Nikhat J. Ghouse \\ American University, USA
}

\section{Introduction}

Assessing diversity, equity, and inclusion (DEI) in US academic libraries is currently a non-standardized process. Often, efforts to assess DEI have focused on counting the number of librarians or staff of color working in the library, an artificial and limited measure that narrowly equates DEI with staffing. In 2012, the Association of College \& Research Libraries (ACRL) published a list of "Diversity Standards" that expanded the idea of what DEI entailed in libraries, while also increasing the complexity of measuring DEI. ${ }^{1}$ ACRL's "Standards" suggested that, in addition to the diversity of the workforce, DEI competency in libraries also included areas such as delivery of services, organizational dynamics, the development of collections, professional development, and research. ${ }^{2}$ In a similar vein, the American Library Association (ALA) included DEI as one of eight "Key Action Areas" for the Association. ${ }^{3}$ While workforce diversity remained prominent within the goals and strategies of this strategic area, there was also recognition of the importance of DEI within LIS education, professional development, and research endeavors. ${ }^{4}$

But recognizing that DEI is multi-faceted and actually assessing those facets are two very different things. One well-known method for assessing DEI within LIS is ClimateQUAL ${ }^{\circledR}$, a survey offered by the Association of Research Libraries (ARL) to assess "library staff perceptions concerning (a) their library's commitment to the principles of diversity, (b) organizational policies and procedures, and (c) staff attitudes." ${ }^{5}$ While ClimateQUAL offers libraries valuable insight into their DEI workplace and organizational climate from the view of those working in that environment, the focus on employee perceptions limits libraries' ability to assess DEI efforts at a more organizational level. It was one library's need to understand not only their current status in terms of integrating DEI into their organization, but also an interest in assessing their progress from year to year that lead to the initial development of a DEI audit by an independent consultant.

The audit development process identified a need to establish a solid framework for the audit, one based on the principles of Organization Development (OD). The final product drew a high level of interest and initiated a pilot investigation into the usefulness of the audit not only as an assessment tool, but also as a guideline for libraries interested in applying OD to their DEI efforts. This paper briefly details the development of the audit, including the integration of OD, the result of the pilot study of eight academic libraries that helped to test the audit's viability for more wide-spread use, and next steps for those interested in the possibilities that a DEI audit and OD principles have for their library's DEI efforts.

\section{Initial Audit Development}

The development of the first iteration of the audit followed a process of instrument creation similar to that identified for scale development by DeVellis. ${ }^{6}$ Specifically, the process included:

- Conducting a series of interviews with key members of the requesting library to determine their needs and how the audit would be used;

- Reviewing relevant documents including the library's mission, vision, and strategic plans; Diversity Committee meeting minutes; and both library and institutional websites;

- Literature review and identification of supporting frameworks; ${ }^{7}$

- Creation of audit statements and determination of rating system;

- Expert review of audit draft by librarians and researchers engaged with DEI topics; and 
- Initial pilot of the audit by the requesting library.

Both the expert review and the initial pilot identified small adjustments to statement wording and total number of items, as some items were removed while others were added. But the most important outcome of the expert review phase was the suggestion to frame the audit around OD principles, specifically the Galbraith Star Model. ${ }^{8}$ The importance of integrating OD principles into the audit will be discussed in the next section.

\section{History of Organization Development}

The professional practice of OD has been in existence for well over 70 years. It is an interdisciplinary field built upon the thinking and research from business, industrial/organizational psychology, human resources management, communication, and sociology, which makes up the practice that is OD. The most commonly agreed upon definition of OD among its practitioners is from Richard Beckhard, a pioneer in the field of OD:

Organization Development is an effort (1) planned, (2) organization-wide, and (3) managed from the top to (4) increase organization effectiveness and health through (5) planned interventions in the organization's "processes," using behavioral-science knowledge. ${ }^{9}$

A more current definition by Donald L. Anderson states that OD "is the process of increasing organizational effectiveness...through the use of interventions driven by social and behavioral science knowledge." 10

Because of its interdisciplinary nature along with years of research and practice, the OD field has grown and changed significantly over the decades. Anderson writes that there are eight elements of the OD field. The first is laboratory training or T-groups, which is based upon the work of Kurt Lewin, a key contributor to the field. As a social psychologist, Lewin's work contributed to the development of the National Training Lab (NTL) where they studied "patterns of group behavior, social problems, and the influence of leadership on groups." "The next is a trio of models including Lewin's Action Research, Likert's Survey Feedback, and Sociotechnical Systems. ${ }^{12}$ All three of these models contributed significantly to the understanding of groups, their participation, processes, and challenges in making group decisions. The remaining six elements of OD are (1) management practices, (2) quality and employee involvement, (3) organizational culture, (4) change management, strategic change, and reengineering, (5) organizational learning, and (6) organizational effectiveness and employee engagement. The above list does not show the depth and complexities that make up of the field of OD. ${ }^{13}$ Barbara Bunker created a visualization of the subfields within OD that covers the depth and growth of the field over the last sixty-plus years. ${ }^{14}$

\section{OD as an Assessment Tool}

Planned change through OD is carried out by OD consultants who engage with the client system to understand what the presenting concerns or problems are from the leadership of an organization. The work of planned change is process-oriented and most OD consultants utilize the Action Research Cycle process to collect data on a system. There are roughly five points to the Action Research Cycle, which begins with identifying the problem, gathering data, interpreting data, acting on evidence, evaluating results, and next steps. ${ }^{15}$ In academia and library science this would be called assessment. The difference is that these change processes are managed by an OD consultant with the goal of helping the organization with finding solutions to the identified problem. Process consulting as a theory and methodology of helping is what Edgar Schein calls "the creation of a relationship with a client that permits the client to perceive, understand, and act on the process events that occur in the client's internal and external environments..."16 Process consulting engages a client system in "double-loop, or generative learning," with the goal of learning how to learn so that the organization is capable of seeing and creating solutions to their own problems. ${ }^{17}$

An OD consultant will work with the client system and will engage in the Action Research Cycle to collect data. To understand the data gathered, models, theories, or frameworks are utilized to organize and subsequently see what is clearly visible, what was previously unclear, and what could be. There are thousands of models in the field of OD including change management models, models on culture, diversity 
and inclusion, team development models, interpersonal theories, large group interventions, strategic planning, leadership and conflict management, coaching, and more. The best analogy that explains the purpose of OD models is an empty bookshelf: The data collected by an OD consultant will be organized onto this organization system (bookshelf) based on the model's parameters. With the data from these models, OD consultants are able to take the next steps of supporting an organization through a change process.

\section{OD and the DEl Audit Development}

When the second author reviewed the audit, a pattern became visible that aligned with the existing structure of the Galbraith Star Model. The Star Model is not a model for diversity and inclusion, but rather a diagnostic model that can support an OD consultant's efforts to identify, analyze, and interpret data for the purpose of identifying needs. In the field of OD consulting, a diagnostic model collects data on the whole organizationthis is appropriate since DEI efforts ideally affect the whole organization. In this case, the needs were related to DEI in a workplace and organizational climate, so the audit was restructured to reflect the model. The Star Model has five points: Strategy (vision, direction, competitive advantage), Structure (power and authority, reporting relationships, organizational roles), Processes ${ }^{18}$ (networks, processes, teams, integrative roles, matrix structures), Rewards ${ }^{19}$ (goals, scorecards and metrics, values and behaviors, compensation), and People $^{20}$ (staffing and selection, performance feedback, learning and development). The sixth point, External DEI Efforts, ${ }^{21}$ is the final factor for consideration. ${ }^{22}$ The restructured audit made viewing the results clearer and allowed the organization to see the current state of their system and helped them to identify the gaps or areas of concern to address. Two sections of the audit (Strategy and People) and the scoring interpretation for those sections are included as Appendix A and B.

\section{Audit Pilot}

Due to the interest in the audit as a tool that could be used by other academic libraries, a pilot study was scheduled to test the audit across a variety of academic library settings. The purpose of the pilot was to identify issues or concerns with the wording or structure of the audit or the scoring system, to identify aspects of DEI assessment in academic libraries that may not be included in the current audit, and to measure aspects of the audit's reliability and validity. Following a brief presentation about the audit at the 2018 ARL Symposium for Strategic Leadership in Diversity, Equity, and Inclusion, 10 libraries showed initial interest in participating in the pilot. Of those ten libraries, eight officially agreed to participate. Basic information about the piloting libraries is provided in Table 1.

\section{Table 1. Piloting libraries general information}

\begin{tabular}{|l|l|}
\hline Library & Carnegie Classification \\
\hline Pilot Library \#1 (PL1) & Baccalaureate Colleges: Arts \& Sciences Focus; Private, Not-For-Profit \\
\hline Pilot Library \#2 (PL2) & Doctoral Universities: Higher Research Activity; Public \\
\hline Pilot Library \#3 (PL3) & Doctoral Universities: Highest Research Activity; Private, Not-For-Profit \\
\hline Pilot Library \#4 (PL4) & Master's Colleges \& Universities: Larger Programs; Public \\
\hline Pilot Library \#5 (PL5) & Doctoral Universities: Highest Research Activity; Public \\
\hline Pilot Library \#6 (PL6) & Master's Colleges \& Universities: Medium Programs; Public \\
\hline Pilot Library \#7 (PL7) & Master's Colleges \& Universities: Larger Programs; Public \\
\hline Pilot Library \#8 (PL8) & Master's Colleges \& Universities: Larger Programs; Public \\
\hline
\end{tabular}

\section{Pilot Process}

Libraries that participated in the pilot were asked to first identify two to three volunteers from their organization to complete the audit. Having multiple volunteers from one organization would allow for the 
assessment of interrater reliability. Organizations were given the following suggestions for ideal candidates to complete the audit on behalf of the organization:

- A member of the library's administration who has been involved with previous DEI efforts and/or has good knowledge of all the library's work and endeavors.

- A library HR staff member who also participates in other library-wide activities.

- A library assessment officer who collects, analyzes, and produces data on various library activities. Work does not have to be diversity-focused, but it is best if work is not limited to only one department (a library-wide assessment person rather than an instruction assessment person).

- A chair or member of a library diversity committee, if the library diversity committee's efforts are library-wide.

- Any library employee highly involved in the library's DEI efforts regardless of position within the library and who holds a high level of knowledge about the library's inner workings.

Once volunteers were identified, they were asked to complete two phases of the audit. In the first phase, volunteers were able to complete the audit as they normally would-responding to each statement based on their knowledge of the organization. In the second phase, volunteers were asked to provide evaluative feedback about all aspects of the audit including clarity of the instructions, statement wording and difficulty to respond, and clarity of the audit scoring system. Each volunteer then participated in a short (20-minute) Zoom interview to discuss their phase II feedback with the audit developer.

\section{Audit Pilot Results}

The results of the pilot revealed some aspects of the audit that could be altered to improve its usefulness for many academic libraries while also identifying aspects that were seen as beneficial. The following section details the suggested alterations and benefits found across the libraries that piloted the audit, as well as the results of the interrater reliability analysis.

Institutional barriers. Some of the smaller libraries that completed the audit indicated an inability to respond to select statements due to the structure of their institution. For example, respondents from PL\#1 noted they felt unable to rate the libraries' status or progress for the statements related to salary:

- The library has completed a salary study to determine that employees of all backgrounds are paid equitably;

- The library has defined policies in place for tenure (if applicable), salary raises, and/or bonuses.

As these two areas are controlled by the institution, the library would not be able to indicate status or progress. In response to this, the audit structure is being re-evaluated to determine a way for libraries to "deselect" items of this nature so that they do not appear in the audit and negatively impact the library's audit score.

Scoring instructions and interpretation. In general, participants felt the scoring instructions were easy to follow and made sense for rating the audit statements. However, some individuals did question the difference between scoring an item based on Status versus Progress. Two respondents also indicated a sense that Status and Progress were often correlated, making it feel odd to rate items on Progress at a level that was distinctly different from the Status rating. As one of the respondents from PL\#8 shared:

Ranking for both Status and Progress felt difficult sometimes. Separately, I understand the difference between Status and Progress. However, conceptually, it didn't seem like the two should be ranked very differently (i.e., how could you have expert Status, but initiating Progress?).

In response to this, the instructions for scoring Status and Progress will be reviewed to ensure that they are measuring distinctly different aspects of DEI and can logically be rated separately. 
Examples and definitions. While most statements were clearly understood, a few piloting libraries asked for examples and definitions to help them clarify what the audit was asking for. Items that were most flagged as needing examples or definitions included:

- DEI are explicitly addressed in the library's policies.

- The library employs a decision-making process that explicitly includes and addresses DEI.

- The library has created and adopted DEI indicators for the library and all employees.

For these specific items, there was a desire for examples of the types of policies that this could include, and a definition of what was meant by "decision-making process" and "indicators." The review helped to identify jargon that did not necessarily translate from institution to institution. In response to this, the audit will be re-evaluated to determine which statements would benefit from examples (including those identified above), and examples will be developed and included in future audit iterations.

Differentiating between the organization and individuals. While the audit is clearly designed to assess the DEI activities of the whole library, a number of respondents struggled to rate some statements based on their view of whether the library was doing the work, or just a few key individuals. As one respondent from PL\#8 shared in response to the statement The Library has taken DEI related actions that have resulted in an increase in DEI collection development, "Individuals have taken more action on this than the Library as a whole." The other respondent from PL\#8 indicated similar thoughts related to whether they needed to consider the whole library or the actions of one individual when rating a statement: "How concrete/formal must this step be to qualify? Some might include the informal thoughts and actions of a single library employee, others might only include a formal, well documented effort." These comments indicate a need to provide additional guidance for those rating items so that consistency in responses can be maintained.

\section{Reliability and Validity Properties}

While checking the interrater reliability of the audit, it was found that two of the libraries had completed the audit as a pair or group, so there was only one set of ratings for those libraries. Intraclass correlation (ICC) estimates for both Status and Progress and their 95\% confidence intervals were calculated for the remaining six libraries using SPSS statistical package version $24^{23}$ based on a mean-rating $(\mathrm{k}=2$ or $\mathrm{k}=4)$, absoluteagreement, 2-way mixed-effects model. Results are presented in Table 2. The analysis revealed poor interrater reliability for three of the libraries on both Status and Progress scores, including one library with negative ICC scores. ${ }^{24}$ The three remaining libraries showed moderate interrater reliability for both Status and Progress. Even for libraries with moderate ICC scores, the wide range of the confidence intervals indicate poor interrater reliability for the respondents.

The negative ICC indicated possible issues with the wording of some of the statements. A review of individual items and item correlations indicated approximately eight statements where rewording would likely improve respondents' ability to rate the item; however, none of these statements was worded in a way that would indicate a need to reverse code the ratings. Most items did not appear to be problematically worded, leading to the need to further investigate the poor interrater reliability scores. During the follow-up interviews with participants, a potential cause of the low ratings was found in the form of individual perspectives.

Table 2. Interrater reliability results for six out of eight piloting libraries

\begin{tabular}{|l|l|l|l|l|l|l|l|}
\hline Participant Code & $\begin{array}{l}\text { Number of } \\
\text { Raters }\end{array}$ & Status ICC & \multicolumn{2}{l|}{$\begin{array}{l}\text { 95\% Confidence } \\
\text { Interval }\end{array}$} & \multicolumn{2}{l|}{ Progress ICC } & \multicolumn{2}{l|}{$\begin{array}{l}\text { 95\% Confidence } \\
\text { Interval }\end{array}$} \\
\hline PL1 & 2 & .07 & -.43 & .45 & .08 & -.35 & .44 \\
\hline PL2 & 2 & -.60 & -1.92 & .16 & -.40 & -1.40 & .24 \\
\hline PL3 & 4 & .58 & .30 & .77 & .50 & .19 & .71 \\
\hline
\end{tabular}




\begin{tabular}{|l|l|l|l|l|l|l|l|}
\hline Participant Code & $\begin{array}{l}\text { Number of } \\
\text { Raters }\end{array}$ & Status ICC & \multicolumn{2}{l|}{$\begin{array}{l}\text { 95\% Confidence } \\
\text { Interval }\end{array}$} & \multicolumn{2}{l|}{ Progress ICC } & \multicolumn{2}{l|}{$\begin{array}{l}\text { 95\% Confidence } \\
\text { Interval }\end{array}$} \\
\hline PL6 & 2 & .33 & -.17 & .64 & .02 & -.33 & .37 \\
\hline PL7 & 2 & .51 & .07 & .75 & .48 & .03 & .73 \\
\hline PL8 & 2 & .67 & .34 & .83 & .66 & .32 & .83 \\
\hline
\end{tabular}

Individual perspectives. Within the evaluation comments and during the follow-up interviews, it was determined that, while most of the statements on the audit were not difficult to respond to, how each respondent approached the statement varied due to a number of factors. Two of the more salient factors were position within the organization and time at the institution.

Whether a respondent was in an administrative (leadership) position or not appeared to impact their approach to responding to audit statements, with those in leadership positions more likely to rate items more positively (optimistically) than those in lower positions. Similarly, those who had been at their institution for a longer period of time tended to rate statements less optimistically. During follow-up interviews, these respondents often cited prior issues related to DEI at the institution as something they considered when rating the library's current level of DEI involvement. A number of respondents outwardly wondered whether others in their organization would rate items the same way that they did. As one of the respondents from PL\#7 shared:

I thought the questions were purposeful and thought provoking, but I found myself wondering if other people in my library would have had the same/similar responses to the prompts. For instance, would they have rated the library higher in certain areas[?] Would their idea of some, good, and exceptional progress be similar to my perspective[?]

Additional support for the impact of individual perspectives on the ratings of different statements was found in follow-up interviews with the two libraries that completed the audit together. For both institutions, having conversations with someone else often revealed an aspect of DEI work that had not been considered by the other. Each respondent tended to bring a different level of knowledge about DEI efforts to the rating process and having the ability to talk to someone else about that knowledge allowed the library to rate an item more clearly. The respondents at PL\#7 especially noted the value of first completing the audit individually and then meeting as a group to discuss the ratings and come to a consensus about the final score. Based on the results of the interrater reliability analysis and the follow-up interviews, it has been determined that completing the audit as a team will be recommended as a best practice approach.

\section{Conclusion and Next Steps}

This conclusion outlines the next steps being considered and what that will mean for the use of the audit for other libraries.

Addressing wording issues. Primary among the next steps is a need to address the concerns identified with the wording of some items in the audit. One known issue was the use of DEI as one concept. As the respondents from PL\#5 shared:

It's difficult to answer these questions because they assume diversity, equity and inclusion strategies and procedures are one and the same thing while in reality they are different. We may have strengths in equity-such as an equitable pay structure and procedures for raisesbut may not have strengths in diversity where representation in the top echelons of the organization is not at all diverse.

Combining these concepts into one worked for the initial library that the audit was designed for due to their nascent approach to DEI. However, it was expected that other libraries might struggle with this combination 
depending on their level of engagement with DEI work. Efforts to separate these concepts will be explored for the next iteration of the audit. Additionally, changes will be made to clarify other items identified as unclear or problematic in wording, including the addition of definitions and examples throughout the audit.

Along with wording changes, some functionality issues will be addressed. This will include providing access to the scoring information throughout the audit; allowing those who are completing the audit to access, save, and make changes to their submissions; and providing a more detailed report of audit results that ties more directly to the rated statements. One item that some libraries wanted was a way to collect information on the DEI activities they were engaged in that matched the different sections of the audit. With this in mind, the ability to create an inventory of activities will be added to the audit. This will allow libraries to not only indicate what efforts are in place to address each statement, but also assist in tracking activities from year to year. This information will also assist libraries with scoring Status and Progress from year to year, as they can assess specific efforts identified during the previous year's inventory.

Also within the considerations for next steps is how to best support libraries that utilize the audit and identify a need for a more in-depth and intensive review of their organizational structure in relation to their DEI efforts. The audit provides organizations with a picture of their current state regarding DEI effortsonly one level of knowledge. Knowing what actions to take to help transition to an inclusive organization is ideally done with the support of an OD consultant. Utilizing process consulting, OD consultants work to create a relationship with the client that permits them to perceive, understand, and act on the process of events that occur and to improve upon the current state. It is recommended that those who utilize the audit also consider the value of working with an OD consultant.

The issues related to DEI are complex and not always clearly seen or quickly solved. Creating inclusive organizations takes intentional work and understanding. We must recognize that libraries are built on whiteness. Before the Civil Rights Act of 1964, black and brown people were intentionally excluded from accessing the knowledge housed in libraries. Whether we are aware of it or not, this exclusion continues in many different forms today. We need to look at ourselves as a field and our organizational cultures without continuing to see DEI as a separate and not equal aspect of the work we do. This audit is one step towards that integration.

-Copyright 2019 Kawanna Bright and Nikhat J. Ghouse 


\section{Endnotes}

1. ACRL, "Diversity Standards."

2. ACRL, "Diversity Standards."

3. ALA, "American Library Association Strategic Directions."

4. ALA, "American Library Association Strategic Directions."

5. ARL, "About: What is ClimateQUAL?"

6. DeVellis, Scale Development.

7. The Social Inclusion Audit created by the Canadian Urban Libraries Council served as an initial guide for development of the audit in terms of structure. Canadian Urban Libraries Council, "Social Inclusion Audit."

8. Galbraith, "The Star Model."

9. Beckhard, Organization Development, 9.

10. Anderson, Organization Development, 3.

11. Anderson, Organization Development, 19.

12. Anderson, Organization Development, 22-24.

13. Anderson, Organization Development, 18-19.

14. Bunker, "A Short History of OD."

15. French and Bell, Jr., Organization Development.

16. Schein, Process Consultation Revisited, 20.

17. Schein, Process Consultation Revisited, 19.

18. Known as Processes \& Lateral Capabilities in the Galbraith Model. Anderson, Organization Development, 304.

19. Known as Reward Systems in the Galbraith Model. Galbraith, Anderson, Organization Development, 304.

20. Known as People Practices in the Galbraith Model. Anderson, Organization Development, 304.

21. Known as external environment in the Galbraith Model. Anderson, Organization Development, 304.

22. Galbraith, Designing Organizations.

23. IBM, IBM SPSS Statistics for Windows.

24. The classification of ICC scores as "poor" or "moderate" are based on the recommendations offered by Koo and Li. Koo and Li, "A Guideline of Selecting," 158.

\section{Bibliography}

American Library Association. "American Library Association Strategic Directions.” Accessed October 13, 2018. http://www.ala.org/aboutala/sites/ala.org.aboutala/files/content/governance/StrategicPlan /Strategic\%20Directions\%202017_Update.pdf.

Anderson, Donald L. Organization Development: The Process of Leading Organizational Change. Los Angeles: SAGE, 2017.

Association of College \& Research Libraries. "Diversity Standards: Cultural Competency for Academic Libraries." Guidelines, Standards, and Frameworks. Accessed October 13, 2018.

http://www.ala.org/acrl/standards/diversity.

Association of Research Libraries. “About: What is ClimateQUAL ${ }^{\circledR} ?$ ” ClimateQUAL ${ }^{\circledR}$ Organizational Climate and Diversity Assessment. Accessed October 13, 2018. https://www.climatequal.org/about.

Beckhard, Richard. Organization Development: Strategies and Models. Reading, MA: Addison-Wesley, 1969.

Bunker, Barbara. “A Short History of OD.” Practicing Social Change (2010): 38-40. http://www.ntlpsc.org/assets/Uploads/PSC-Journal-Issue-02-Academics-Corner.pdf.

Canadian Urban Libraries Council. "Social Inclusion Audit.” Accessed October 19, 2018.

http://www.siatoolkit.com/\#axzz5ExeirtRa. 
DeVellis, Robert F. Scale Development: Theory and Applications. Los Angeles: Sage, 2012.

French, Wendell L., and Cecil H. Bell, Jr. Organization Development: Behavioral Science Interventions for Organizational Improvements, $6^{\text {th }}$ ed. Upper Saddle River, NJ: Prentice Hall, 1999.

Galbraith, Jay R. Designing Organizations: An Executive Guide to Strategy, Structure, and Process. San Francisco: Jossey-Bass, 2002.

Galbraith, Jay R. "The Star Model ${ }^{\mathrm{TM}}$.” Accessed October 19, 2018. http://www.jaygalbraith.com/images/pdfs /StarModel.pdf.

IBM Corp. IBM SPSS Statistics for Windows, Version 24.0. Armonk, NY: IBM Corp, 2016.

Koo, Terry K. and Mae Y. Li. "A Guideline of Selecting and Reporting Intraclass Correlation Coefficients for Reliability Research.” Journal of Chiropractic Medicine 15, no. 2 (June 2016): 155-163.

https://www.ncbi.nlm.nih.gov/pmc/articles/PMC4913118/.

Schein, Edgar H. Process Consultation Revisited: Building the Helping Relationship. Reading, MA: AddisonWesley, 1999. 
Appendix A: Audit "Strategy" Section and Scoring Interpretation

\begin{tabular}{|c|c|c|c|c|c|c|c|c|c|c|}
\hline & \multicolumn{5}{|c|}{ Status } & \multicolumn{5}{|c|}{ Progress } \\
\hline & $\begin{array}{l}\text { Non- } \\
\text { Existent }\end{array}$ & Novice & Intermediate & Advanced & Expert & $\begin{array}{l}\text { Non- } \\
\text { Existent }\end{array}$ & Initiating & Improving & Stable & Evolving \\
\hline $\begin{array}{l}\text { DEI are explicitly addressed in the Library's } \\
\text { strategic plan }\end{array}$ & $\bigcirc$ & $\mathrm{O}$ & $\mathrm{O}$ & $\mathrm{O}$ & $\bigcirc$ & $\mathrm{O}$ & $\mathrm{O}$ & $\mathrm{O}$ & $\mathrm{O}$ & 0 \\
\hline $\begin{array}{l}\text { DEI are explicitly addressed in the Library's } \\
\text { mission, vision, and values' statement }\end{array}$ & $\bigcirc$ & 0 & 0 & $\mathrm{O}$ & 0 & 0 & $\mathrm{O}$ & 0 & $\mathrm{O}$ & 0 \\
\hline $\begin{array}{l}\text { DEl are explicitly addressed in the Library's } \\
\text { policies }\end{array}$ & 0 & 0 & 0 & $\mathrm{O}$ & 0 & 0 & $\mathrm{O}$ & 0 & $\mathrm{O}$ & 0 \\
\hline $\begin{array}{l}\text { A DEI plan of action to address identified } \\
\text { gaps and needs has been developed }\end{array}$ & $\bigcirc$ & $\mathrm{O}$ & $\mathrm{O}$ & $\mathrm{O}$ & $\bigcirc$ & $\mathrm{O}$ & $\mathrm{O}$ & 0 & $\mathrm{O}$ & 0 \\
\hline
\end{tabular}

\begin{tabular}{|l|l|l|}
\hline Score Range & Status Interpretation & Progress Interpretation \\
\hline $\mathbf{0 - 4}$ & $\begin{array}{l}\text { Little to no work has been done to integrate DEI into } \\
\text { strategic planning efforts. }\end{array}$ & $\begin{array}{l}\text { Little progress has been made towards integrating DEI } \\
\text { into the Library's strategic planning efforts. }\end{array}$ \\
\hline $\mathbf{5 - 8}$ & $\begin{array}{l}\text { Some work is being done to integrate DEI into strategic } \\
\text { planning efforts, but mostly in the form of discussion } \\
\text { and planning. }\end{array}$ & $\begin{array}{l}\text { Some progress has been made towards integrating DEI } \\
\text { into the Library's strategic planning efforts. }\end{array}$ \\
\hline $\mathbf{9 - 1 2}$ & $\begin{array}{l}\text { Demonstrable work is being done to integrate DEI into } \\
\text { strategic planning efforts, though most activities are } \\
\text { very recently implemented. }\end{array}$ & $\begin{array}{l}\text { Moderate progress has been made towards integrating } \\
\text { DEI into the Library's strategic planning efforts. }\end{array}$ \\
\hline $\mathbf{1 3 - 1 6}$ & $\begin{array}{l}\text { Significant work is being done to integrate DEI into } \\
\text { strategic planning efforts. Most outcomes have been } \\
\text { fully addressed and activities fully implemented. }\end{array}$ & $\begin{array}{l}\text { Significant progress has been made towards integrating } \\
\text { DEI into the Library's strategic planning efforts. }\end{array}$ \\
\hline
\end{tabular}




\begin{tabular}{|c|c|c|c|c|c|c|c|c|c|c|}
\hline & \multicolumn{5}{|c|}{ Status } & \multicolumn{5}{|c|}{ Progress } \\
\hline & $\begin{array}{c}\text { Non- } \\
\text { Existent }\end{array}$ & Novice & Intermediate & Advanced & Expert & $\begin{array}{l}\text { Non- } \\
\text { Existent }\end{array}$ & Initiating & Improving & Stable & Evolving \\
\hline $\begin{array}{l}\text { The Library has assessed the demographic } \\
\text { profile of its internal community and } \\
\text { determined employee diversity levels }\end{array}$ & $\mathrm{O}$ & $\mathrm{O}$ & 0 & $\mathrm{O}$ & 0 & 0 & $\mathrm{O}$ & 0 & $\mathrm{O}$ & $\mathrm{O}$ \\
\hline $\begin{array}{l}\text { The Library understands the DEI needs of its } \\
\text { internal community's different cultural groups }\end{array}$ & 0 & 0 & 0 & $\mathrm{O}$ & 0 & 0 & $\mathrm{O}$ & 0 & $\mathrm{O}$ & 0 \\
\hline $\begin{array}{l}\text { The Library has developed strategies to } \\
\text { increase employee diversity }\end{array}$ & $\bigcirc$ & $\bigcirc$ & $\bigcirc$ & $\mathrm{O}$ & $\bigcirc$ & $\bigcirc$ & $\mathrm{O}$ & $\bigcirc$ & $\mathrm{O}$ & $\bigcirc$ \\
\hline $\begin{array}{l}\text { The Library has taken DEI related actions } \\
\text { that have resulted in increased employee } \\
\text { diversity }\end{array}$ & $\mathrm{O}$ & 0 & $\mathrm{O}$ & 0 & $\mathrm{O}$ & $\mathrm{O}$ & $\mathrm{O}$ & 0 & $\mathrm{O}$ & 0 \\
\hline $\begin{array}{l}\text { The Library has created and adopted DEI } \\
\text { indicators for the Library and all employees }\end{array}$ & $\mathrm{O}$ & $\bigcirc$ & $\bigcirc$ & $\mathrm{O}$ & $\bigcirc$ & $\bigcirc$ & $\mathrm{O}$ & $\bigcirc$ & $\mathrm{O}$ & $\bigcirc$ \\
\hline
\end{tabular}

\begin{tabular}{|l|l|l|}
\hline Score Range & Status Interpretation & Progress Interpretation \\
\hline $\mathbf{5}$ & $\begin{array}{l}\text { Little to no work has been done to address issues related to the } \\
\text { DEI of library employees. }\end{array}$ & $\begin{array}{l}\text { Little progress has been made towards addressing issues related } \\
\text { to the DEI of library employees. }\end{array}$ \\
\hline $\mathbf{6 - 1 0}$ & $\begin{array}{l}\text { Some work is being done to address issues related to the DEI of } \\
\text { library employees, but mostly in the form of discussion and } \\
\text { planning. }\end{array}$ & $\begin{array}{l}\text { Some progress has been made towards addressing issues related } \\
\text { to the DEI of library employees. }\end{array}$ \\
\hline $\mathbf{1 1 - 1 5}$ & $\begin{array}{l}\text { Demonstrable work is being done to address issues related to the } \\
\text { DEI of library employees, though most activities are very recently } \\
\text { implemented. }\end{array}$ & $\begin{array}{l}\text { Moderate progress has been made towards addressing issues } \\
\text { related to the DEI of library employees. }\end{array}$ \\
\hline $\mathbf{1 6 - 2 0}$ & $\begin{array}{l}\text { Significant work is being done to address issues related to the DEI } \\
\text { of library employees. Most outcomes have been fully addressed } \\
\text { and activities fully implemented. }\end{array}$ & $\begin{array}{l}\text { Significant progress has been made towards addressing issues } \\
\text { related to the DEI of library employees. }\end{array}$ \\
\hline
\end{tabular}

